\title{
Erratum to: Properties of geothermal resources in Kebilli region, Southwestern Tunisia
}

Fatma Ben Brahim • Jalila Makni • Salem Bouri · Hamed Ben Dhia

Published online: 5 October 2012

(c) Springer-Verlag Berlin Heidelberg 2012

Erratum to: Environ Earth Sci

DOI 10.1007/s12665-012-1974-7

Unfortunately, one of the co-author Dr. Hamed Ben Dhia has not been included in the original publication.

The complete author list should read as follows: "Fatma Ben Brahim, Jalila Makni, Salem Bouri, Hamed Ben Dhia".

The online version of the original article can be found under doi:10.1007/s12665-012-1974-7.

F. Ben Brahim $(\bowtie) \cdot$ J. Makni $\cdot$ S. Bouri $\cdot$ H. Ben Dhia Water, Energy and Environment Laboratory (LR3E), National School of the Engineers, B.p.w.3038 Sfax, Tunisia e-mail: bfatma27@yahoo.fr 